\title{
Use of recycled tires in non-structural concrete
}

\author{
Zamzam Al Rawahi, ${ }^{1, *}$, and Muhammad Bilal Waris ${ }^{2}$ \\ ${ }^{1}$ Sultan Qaboos University, Department of Civil and Arch. Engineering, P.O Box: 33, Al-Khoud 123, \\ Muscat, Sultanate of Oman \\ ${ }^{2}$ Sultan Qaboos University, Department of Civil and Arch. Engineering, P.O Box: 33, Al-Khoud 123, \\ Muscat, Sultanate of Oman
}

\begin{abstract}
This research addresses the issue of tire waste management and natural aggregate resource depletion. It investigates use of commercially produced recycled tire rubber as replacement for fine and coarse aggregate in non-structural concrete. Two replacement levels of $10 \%$ and $20 \%$ were considered for fine aggregate with $0 \%$ or $10 \%$ of coarse aggregate. The study employed a mix proportion of 1:5:4 (cement: fine aggregate: coarse aggregate) with a water-to-cement ratio of 0.25 , which is normally utilized in concrete block manufacturing in Oman. The mixes were tested for their thermal conductivity, water absorption and compressive strength. The behavior of mixes exposed to 100 and $200^{\circ} \mathrm{C}$ was also studied and the samples were later tested for compressive strength. The results showed improvements in compressive strength after exposure to heat. Thermal conductivity was reduced as the percentage replacement increased for both fine and coarse aggregate. During heat exposure, the temperature rise was faster in rubberized mixes, and the compressive strength of all mixes improved after the exposure to heat. Water absorption and void content increased with increase in replacement percentage. The compressive strength did not show a clear trend with the replacement and this is due to the sensitivity of the stiff mix used in the study and its inherent lean nature. The results indicate that the lean nature of the mix makes it insensitive to small replacement investigated in this research.
\end{abstract}

\section{Introduction}

Tire waste represents serious health and environmental concern in many ways. Waste tires from vehicles are often improperly stored and disposed in Oman by either disposal into stockpiles or illegal dumping. The lack of proper management of these waste tires presents a potential threat to human health and environment [1]. On the other hand, saving natural resources utilized in form of aggregate is a concern. Concrete could be one of the possible solutions for the utilization of this tire waste and conserve the natural resources.

Several studies have been conducted to investigate use of tire rubber waste in concrete. The studies where carried out by replacing fine and coarse aggregate with fine and coarse

\footnotetext{
* Corresponding author: zamzam7793@gmail.com
} 
tire rubber in different replacements percentage. According to previous researchers, it is recommended to replace no more than $30 \%$ of fine aggregate. With super fine rubber (500600 micron) [2], the crump rubber enhances sound insulation and thermal conductivity properties of the resulting concrete [3]. Also, the larger the rubber particle size, the higher the effect on compressive strength [4] and as the percentage replacement increased the compressive strength decrease [1-2, 5-6]. Water absorption increases as the percentage replacement increase [1,5-6]. In addition, the use of tire replacements in structural concrete is likely to face loss in strength, hence, its application to non- structural concrete is more suitable [2].

Therefore, this paper shall investigate the use of tire waste rubber in non-structural concrete as fine and coarse aggregate replacements with different replacement proportions, and study physical properties of the rubberized concrete including water absorption, thermal conductivity and compressive strength. Also, it shall verify the conformance of the rubberized concrete with the specified standards for non- structural concrete.

\section{Experimental program}

\subsection{Specifications}

This research investigates the performance of rubberized concrete mix to be used in nonstructural concrete that follow two standards, Oman Concrete Products (OCP) and ASTM Standards. Oman Concrete Products [7] is one of the leading companies in Oman in the field of infrastructure construction. It has ISO 9001-2000 certification. Materials produced by OCP are designed based on a combination of several international standards and also environmental, economical, and technical factors specific to construction in Oman [2]. This research uses a mix proportion of 1:5:4 (cement: fine aggregate: coarse aggregate) and w/c ratio of 0.25 according to $\mathrm{OCP}$.

\subsection{Materials}

Materials used in this study include Ordinary Portland cement (Type 1/ ASTM C150 [8]), $10 \mathrm{~mm}$ natural course aggregate, fine aggregate, tap water, crumb tires $(<20 \mathrm{~mm}$ as coarse aggregate replacement and $0.8-4 \mathrm{~mm}$ as fine aggregate replacement). Specific gravity and water absorption for coarse and fine aggregate were tested according to ASTMC127 [9] and ASTM C128 [10] respectively. Water absorption for tire rubber was measured and calculated according to ASTMD570 [11]. Physical properties of aggregate and tire rubber are shown in Table 1. Figure 1(a) shows the gradation curve of fine aggregate and fine tire rubber. It is clear that approximately $60 \%$ of tire crumps are within the size range 1.18 $2.36 \mathrm{~mm}$. Figure 1(b) shows the gradation curve of coarse aggregate and coarse rubber. Coarse tire crumps varied between 2.36 and $14 \mathrm{~mm}$ in size.

Table 1. Physical properties of aggregate and tire rubber.

\begin{tabular}{|c|c|c|}
\hline Material & \%Absorption & Specific Gravity \\
\hline Coarse Aggregate & 3.63 & 2.77 \\
\hline Fine Aggregate & 3.34 & 2.68 \\
\hline Fine Crumped Rubber & 3.48 & 1.05 \\
\hline Coarse Crumped Rubber & 5.57 & 1.05 \\
\hline
\end{tabular}




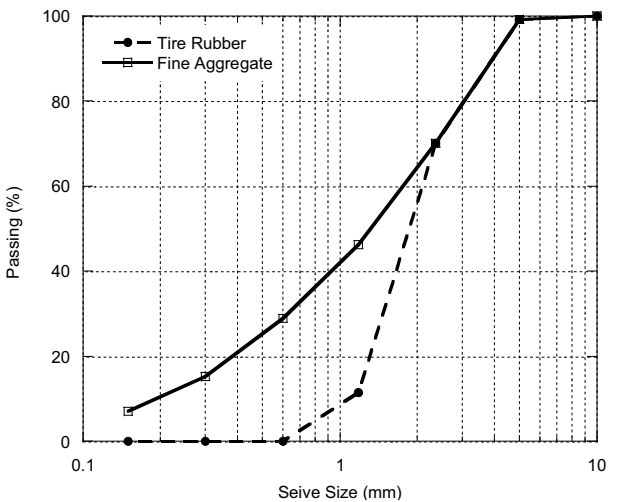

(a) Fine aggregate and tire rubber $(0.8-4$ $\mathrm{mm})$

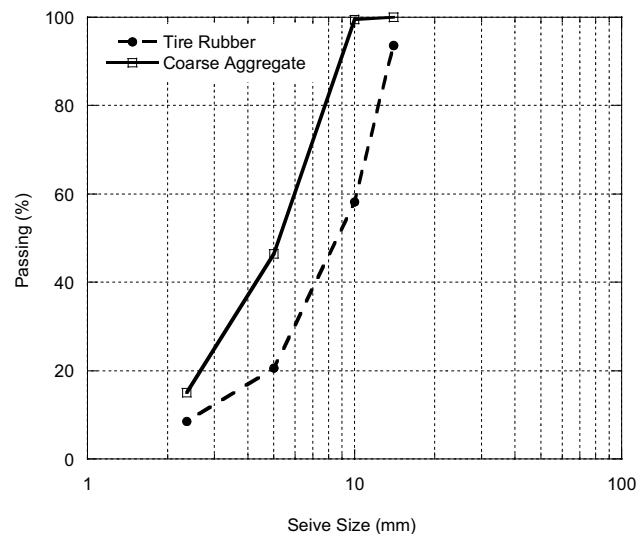

(b)Coarse aggregate and tire rubber.

Fig. 1. Particle size distribution of natural aggregate and tire rubber.

A control mix (CM) will be produced with 2 sets of mixes. Set 1 has $0 \%$ coarse aggregate replacement (CAR) and set 2 has $10 \%$ coarse aggregate replacement. Each set will have $10 \%$ and $20 \%$ fine aggregate replacements (FAR). The experimental test scheme is summarized in Table 2.

Table 2. Experimental test scheme.

\begin{tabular}{|c|c|c|c|c|c|}
\hline & Control mix & Set 1 & \multicolumn{2}{c|}{ Set 2 } \\
\hline Coarse aggregate replacement (CAR) & $0 \%$ & \multicolumn{2}{|c|}{$0 \%$} & \multicolumn{2}{|c|}{$10 \%$} \\
\hline Fine aggregate replacement (FAR) & $0 \%$ & $10 \%$ & $20 \%$ & $10 \%$ & $20 \%$ \\
\hline
\end{tabular}

\subsection{Specimen preparation and testing}

Concrete was casted according ASTM C192 [12] using a vibration table. Despite the stiff mix produced, no segregation was observed as it can be observed in Figure 2. All the samples were cured for 28 days at room temperature.

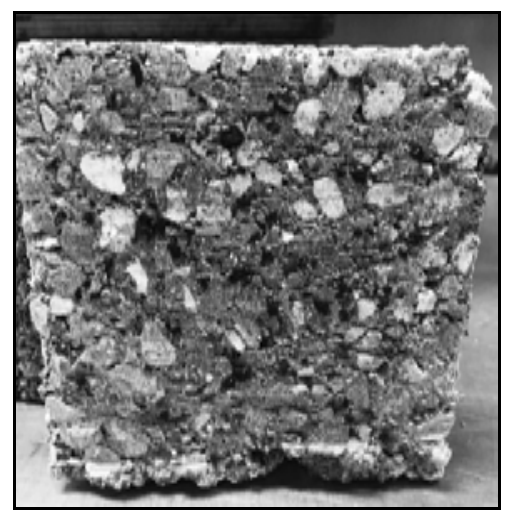

Fig. 2. Cross section of $100 \mathrm{~mm}$ cube with CAR-0\%, FAR-10\%. 
Four tests were carried out: thermal conductivity (Figure 3), water absorption, compressive strength and heating test (Figure 4). Heating test is a non-standard test where concrete is exposed to heat at 2 different temperatures, 100 and $200^{\circ} \mathrm{C}$. The temperature was measured using thermocouples, 1 inside each cube and one in the oven to indicate the temperature at the surface of the cube. The cubes were then inserted in the furnace and the thermocouples were plugged into the data logger to take a reading of the temperature every 10 seconds. Table 3 lists the investigated mechanical and physical properties of hardened concrete along with the standards used and cubes size. Three specimens were tested for each mix and the property is reported as the average of the three values.

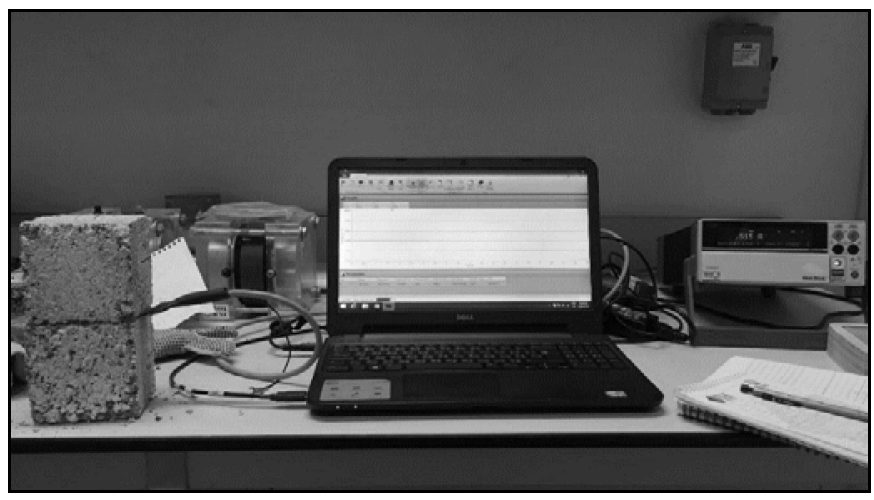

Fig. 3. Setup for thermal conductivity test.

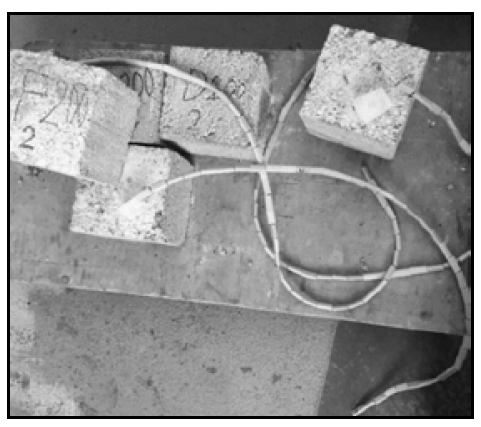

(a) Cubes with thermocouples inside for heating test

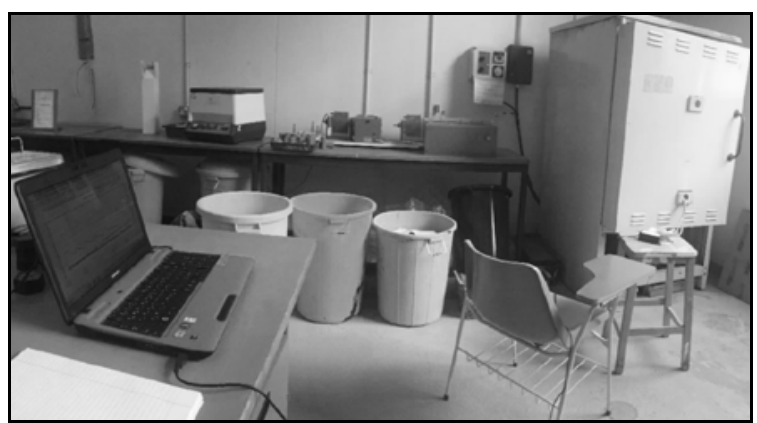

(b) Apparatus used for heating test.

Fig. 4. Setup for investigating behavior under exposure to heat.

Table 3. Tests on hardened concrete

\begin{tabular}{|c|c|c|}
\hline Property Test & Sample Size & Test Standard \\
\hline Thermal Conductivity & $100 \mathrm{~mm} \mathrm{Cube}$ & ISO 22007-2 [13] \\
\hline Water Absorption & $100 \mathrm{~mm}$ Cube & ASTM C 642 [14] \\
\hline Compressive Strength & $150 \mathrm{~mm}$ Cube & BS EN 12390 [15] \\
\hline Heating Test & $150 \mathrm{~mm} \mathrm{Cube}$ & -- \\
\hline
\end{tabular}




\section{Results and analysis}

\subsection{Thermal conductivity test}

Figure 5 presents the results of thermal conductivity, which decreased as the percentage replacement increased. Thermal conductivity of the control mix was found to be 1.0174 $\mathrm{W} / \mathrm{mK}$, while for those with FAR-10\% and FAR-20\% of CAR- $0 \%$ mix were found to be 0.9505 and $0.8848 \mathrm{~W} / \mathrm{mK}$ respectively. For CAR $-10 \%$ mixes, thermal conductivity of FAR- $10 \%$ was found at $0.9692 \mathrm{~W} / \mathrm{mK}$, while it was $0.8890 \mathrm{~W} / \mathrm{mk}$ for FAR-20\%. Low values of thermal conductivity for mixes with tire rubber indicate that rubberized concrete has a better insulation than plain concrete and this is partly be due to the low density of rubberized concrete samples.

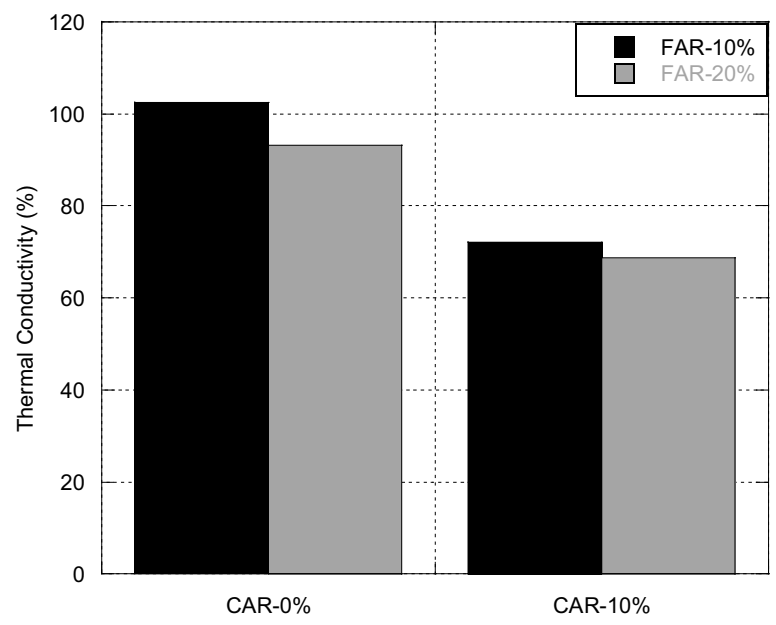

Fig. 5. Thermal conductivity.

\subsection{Water absorption test}

Table 4 shows the results for water absorption, bulk density and percentage voids in the mixes. As shown in Table 4, the rubberized concrete exhibited lighter density than plain concrete. The reduction in the bulk density is mainly due to the replacement of a heavier material (aggregate) by a lighter material (tire rubber). Replacement of fine and coarse aggregate by rubber influence the porosity of concrete which affects the water absorption capacity of concrete. It can be observed from Table 4 that water absorption percentage did not exceed the limit specified by OCP based on BS 6073 [16], which is $15 \%$. The water absorption of rubberized concrete is, therefore, still acceptable. Samples with no CAR has a higher water absorption percentage than samples with CAR-10\%. The reason behind this inverse relationship may be due to the sensitivity of the mixes to variation in compaction due improvement in workability with addition of rubber as reported in previous studies [1, 2]. 
Table 4. Results of water absorption test.

\begin{tabular}{|c|c|c|c|c|c|}
\hline Set & CM & \multicolumn{2}{|c|}{$\mathbf{1}$} & \multicolumn{2}{c|}{$\mathbf{2}$} \\
\hline Coarse Aggregate Replacement (CAR) & $\mathbf{0 \%}$ & \multicolumn{2}{|c|}{$\mathbf{0 \%}$} & \multicolumn{2}{|c|}{$\mathbf{1 0 \%}$} \\
\hline Fine Aggregate Replacement (FAR) & $\mathbf{0 \%}$ & $\mathbf{1 0 \%}$ & $\mathbf{2 0 \%}$ & $\mathbf{1 0 \%}$ & $\mathbf{2 0 \%}$ \\
\hline Weight $(\mathrm{kg})$ & 2.13 & 2.03 & 1.93 & 1.96 & 1.96 \\
\hline Bulk Density $\left(\mathrm{kg} / \mathrm{m}^{3}\right)$ & 1990 & 1920 & 1930 & 1960 & 1950 \\
\hline Absorption (\%) & 12.93 & 13.25 & 12.05 & 9.32 & 8.88 \\
\hline Voids (\%) & 30.75 & 30.52 & 27.77 & 22.48 & 21.19 \\
\hline
\end{tabular}

\subsection{Compressive strength test}

The weights and compressive strength values of 28 days samples are presented in Table 5. Samples with CAR- $0 \%$ have a higher compressive strength value than samples with CAR$10 \%$ as it can be observed from Figure 6 . Also, as the fine aggregate replacement increased, the compressive strength decreased and this can be clearly observed at CAR-10\% mixes. These results indicate that as the percentage replacement increased, the compressive strength decreased. However, the effect of fine aggregate replacement is reversed in CAR$0 \%$ mixes, as the percentage replacement increased, the compressive strength increased. This may be due to variation in the compaction effort since it is a manual process as previously explained.

Table 5. Summary of weights and compressive strength values.

\begin{tabular}{|c|c|c|c|c|c|}
\hline Set & CM & \multicolumn{2}{|c|}{$\mathbf{1}$} & \multicolumn{2}{|c|}{$\mathbf{2}$} \\
\hline CAR & $\mathbf{0 \%}$ & \multicolumn{2}{|c|}{$\mathbf{0 \%}$} & \multicolumn{2}{|c|}{$\mathbf{1 0 \%}$} \\
\hline FAR & $\mathbf{0 \%}$ & $\mathbf{1 0 \%}$ & $\mathbf{2 0} \%$ & $\mathbf{1 0 \%}$ & $\mathbf{2 0 \%}$ \\
\hline Weight $(\mathrm{kg})$ & 7.03 & 6.82 & 6.75 & 6.63 & 6.48 \\
\hline Compressive Strength $(\mathrm{MPa})$ & 2.95 & 3.48 & 4.74 & 3.20 & 3.02 \\
\hline
\end{tabular}

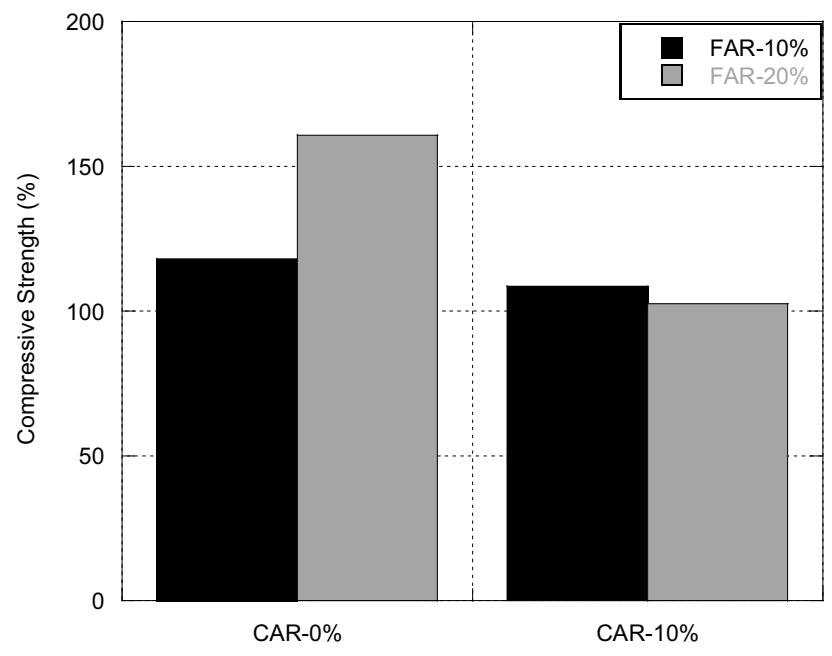

Fig. 6. Compressive strength test results as percentage of control mix. 


\subsection{Heating test}

The temperature gradient at the core of $150 \mathrm{~mm}$ cube during exposure to $100^{\circ} \mathrm{C}$ for 3 hours is shown in Figure 7. Figure 8 shows the temperature gradient at $200^{\circ} \mathrm{C}$ for 6 hours. The data was collected at $10 \mathrm{sec}$ intervals but an average of one minute is reported in the graphs. For $100^{\circ} \mathrm{C}$, all mixes of CAR- $0 \%$ reached a temperature of approximately $60^{\circ} \mathrm{C}$ after 3 hours, while for the CAR-10\%, the FAR- $20 \%$ reached a temperature of nearly $70^{\circ} \mathrm{C}$. For $200^{\circ} \mathrm{C}$, in CAR- $0 \%$ all mix shows near similar behavior as the control mix with slight variations. For the CAR-10\%, the FAR-10\% shows almost identical behavior has the control mix while the FAR-20\% clear steep temperature gradient. Relating the results to the thermal conductivity test, there was heat dissipation in the thermal conductivity test through the sides exposed to the environment while in case of the oven heating all the sides were exposed to heat and hence it showed a low thermal insulation. For the $200^{\circ} \mathrm{C}$, a plateau is observed in all mixes at $100^{\circ} \mathrm{C}$, this could be a result of thermo-chemical changes in the concrete matrix due to complete evaporation of free and bonded water.

The heat exposure was extended until the core reached thermal equilibrium. The compressive strength test was carried out for these cubes to investigate the effect of exposure to high temperature. It can be observed from Figure 9 that the compressive strength of all mixes has improved after heat exposure. When the concrete samples are heated $\left(<300^{\circ} \mathrm{C}\right)$, free water evaporates first, followed by capillary water, and finally by physically bound water. The evaporated water will provide a moist environment inside the oven so hydration reactions may take place. In these conditions, hydration process is accelerated that increases strength of concrete [17].
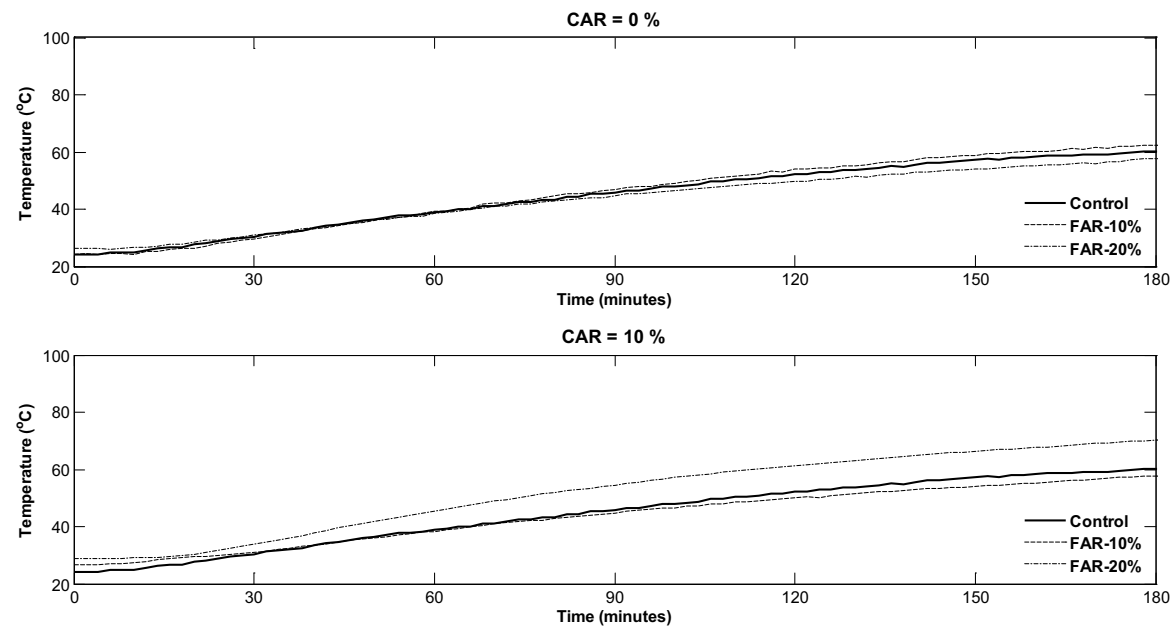

Fig. 7. Temperature gradient for all mixes at $100^{\circ} \mathrm{C}$. 

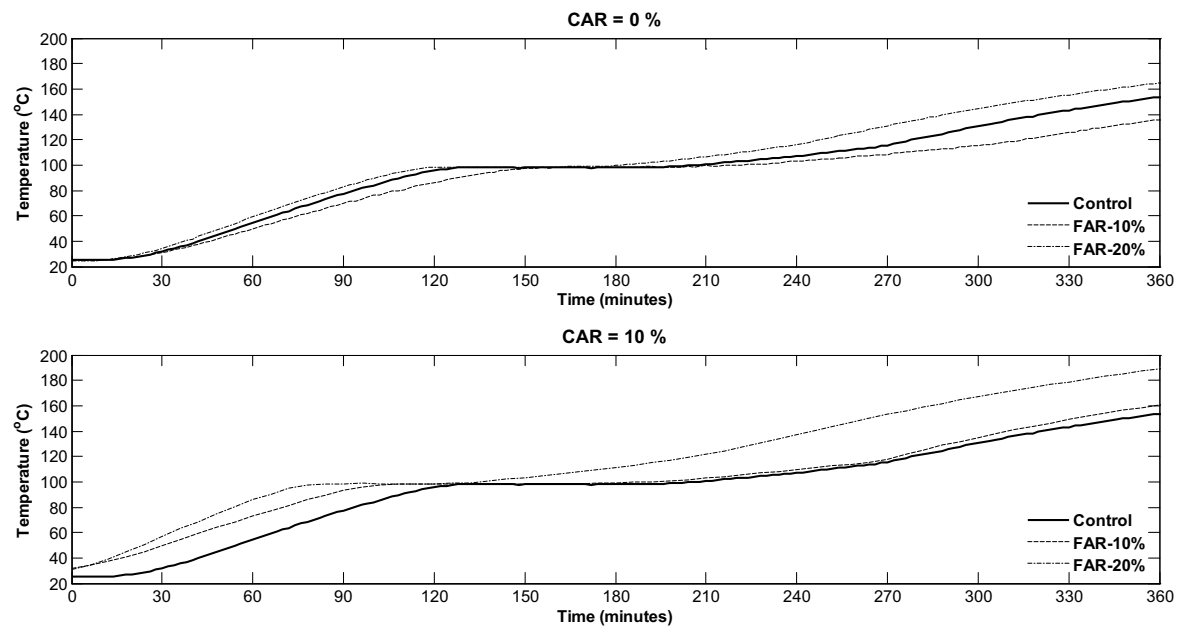

Fig.8. Temperature gradient for all mixes at $200^{\circ} \mathrm{C}$.

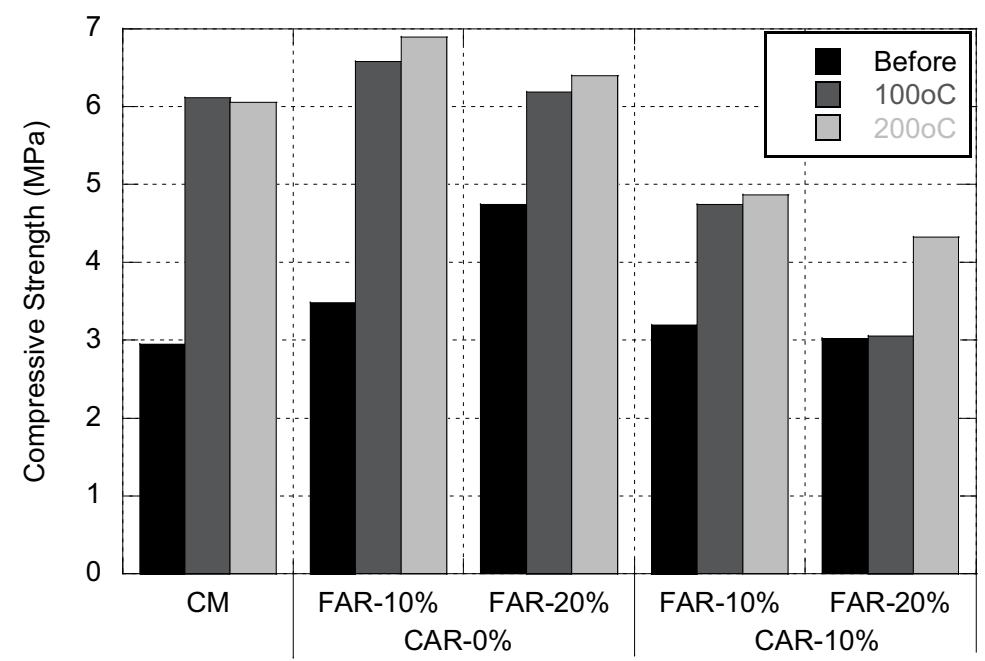

Fig. 9. Compressive strength of samples before and after exposure to 100 and $200^{\circ} \mathrm{C}$.

\section{Conclusion}

Five concrete mixes have been studied in this research with two levels of replacement for fine aggregate and one for coarse aggregate. Mix proportion and w/c ratio were kept constant as 1:5:4 (cement: fine aggregate: coarse aggregate) and 0.25 respectively. The samples were tested for their thermal conductivity, water absorption, compressive strength and heat exposure. Rubberized concrete provides better thermal insulation properties as seen by decreasing thermal conductivity values as compared to those with no or less rubber content. Water absorption of rubberized concrete mixes was not greatly affected by the replacement. All water absorption values did not exceed the maximum limit specified by OCP which is $15 \%$. Voids content in rubberized concrete can be reduced by a better compaction effort or by adding superplasticizer to improve the workability and hence 
reduce the void content. Compression strength is relatively insensitive to the replacement due to the lean nature of the mix. Since the void content was found to be slightly higher in rubberized concrete compared to those with no or less tire replacement, the heat penetrates easily and rapidly into the rubberized concrete samples at exposure to heat. The compressive strength of the samples has improved after heat exposure at $100^{\circ} \mathrm{C}$ and $200^{\circ} \mathrm{C}$. The overall performance of concrete under replacement was good and shows evident improvements in the the compressive strength after heating and in thermal insulation.

\section{References}

1. Ali, N. 'Utilization of Recycled Tires for Aggregate Replacement in Concrete', Research Project Report, Sultan Qaboos University, Oman (2013).

2. Najwani, H. 'Use of Recycled Rubber in Non-Structural Concrete', Research Project Report, Sultan Qaboos University, Oman (2015).

3. Sukontasukkul, P. and Wiwatpattanapong, S. 'Lightweight Concrete Mixed with Superfine Crumb Rubber Powder Part 1: Insulation Properties', KMUTNB, 19(3), p. 2552 (2009).

4. Lijuan, L. Shenghua, R. Lan, Z. 'Mechanical properties and constitutive equations of concrete containing a low volume of tire rubber particles', Construction and Building Materials, 70, pp. 291-308 (2014).

5. Gupta, T., Chaudhary, S .and Sharma, R. 'Assessment of mechanical and durability properties of concrete containing waste rubber tire as fine aggregate', Construction and Building Materials, 73, pp. 562-574 (2014).

6. Sandeep, V., Kumar, N. and Sudharani, Ch. 'Using Tires Wastes as AggregatesInConcreteToFormRubcrete-MixForEngineeringApplications',IJRET:

International Journal of Research in Engineering and Technology, 3, pp. 2321-7308 (2014).

7. Oman Concrete Products, www.ocpblock.com

8. ASTM C150, Standard Specification for Portland Cement.

9. ASTM C127-15, Standard Test Method for Relative Density (Specific Gravity) and Absorption of Coarse Aggregate.

10. ASTM C128-15, Standard Test Method for Relative Density (Specific Gravity) and Absorption of Fine Aggregate.

11. ASTM D570-98, Standard Test Method for Water Absorption of Plastics.

12. ASTM C192, Standard Practice for Making and Curing Concrete Test Specimens in the Laboratory.

13. ISO 22007-2, Determination of Thermal Conductivity and Thermal Diffusivity - Part 2: Transient Plane Heat Source (Hot Disc) Method.

14. ASTM C642-13, Standard Test Method for Density Absorption and Voids in Hardened Concrete.

15. BS EN12390, Testing Hardened Concrete, Part 3: Compressive Strength of Test Specimens.

16. BS 6073, Precast Concrete Masonry Units. Guide For Specifying Precast Concrete Masonry Units.

17. Al-Jabri, K., Waris, M. and Al-Saidy, A., 'Effect of aggregate and water to cement ratio on concrete properties at elevated temperature', Fire and Materials; 40:913-925 (2015). 